\title{
Degranulation of Leukocytes in
}

\section{Chronic Granulomatous Disease}

\author{
Robert L. Baehner, Morris J. Karnovsky, and Manfred L. Karnovsky \\ From the Departments of Biological Chemistry, Pathology, and Pediatrics, \\ Harvard Medical School, Boston, Massachusetts 02115, and the Division of \\ Hematology of the Department of Medicine, Childrens Hospital Medical \\ Center, Boston, Massachusetts 02115
}

\begin{abstract}
A в STRACT Quantitative chemical analyses of the subcellular distribution patterns for acid and alkaline phosphatase, beta glucuronidase and peroxidase were obtained for human peripheral blood leukocytes of four patients with chronic granulomatous disease (CGD). Five young adults with acute infections served as controls. The observations were made on fractions obtained by homogenization and centrifugation of leukocytes previously incubated with or without particles for ingestion. Distributions in resting CGD and normal cells were very similar for acid and alkaline phosphatase and peroxidase, but the proportion of beta glucuronidase in the granule fraction of CGD cells was depressed, with an increased proportion in the soluble fraction. Release of granule-bound enzymes during phagocytosis of a variety of particles was the same for CGD and control cells, except that release of beta glucuronidase was less marked in CGD cells. Total enzymatic activity of CGD cells for the hydrolases studied was normal. The data indicated that granular enzymes are released in a normal fashion in phagocytizing CGD cells. Supportive evidence of release of enzymes into the phagocytic vacuole of CGD cells was obtained by an electron microscopic study of myeloperoxidase.
\end{abstract}

\section{INTRODUCTION}

Chronic granulomatous disease (CGD) is a genetically determined disorder in which peripheral blood leukocytes fail to destroy certain bacteria during phagocytosis. The patients are afflicted with chronic and recurrent suppurative infections, usually due to Staph-

Address requests for reprints to MLK in the Department of Biological Chemistry, Harvard Medical School, Boston, Mass. 02115.

Received for publication 30 July 1968 and in revised form 23 September 1968. ylococcus aureus. Holmes, Quie, Windhorst, and Good (1) first established that leukocytes from these patients could ingest but could not kill the infecting organisms. Kaplan, Laxdal, and Quie (2) subsequently showed that leukocytes from CGD patients could kill streptococci normally. At the metabolic level, Sbarra and Karnovsky $(3,4)$ previously had established that respiration and oxidation of glucose via the hexose monophosphate pathway are stimulated during phagocytosis by normal leukocytes from guinea pigs. In the CGD cells, Holmes, Page, and Good (5) and Baehner and Nathan (6) noted a lack of these oxidative reactions during phagocytosis, although normal human cells are comparable to those from the guinea pig. The defective cells, initially thought to manifest their abnormalities as a result of an $\mathrm{X}$ chromosome-linked trait, and the cells from the female carriers of the gene for CGD, can be identified by their total or partial inability, respectively, to reduce nitro blue tetrazolium (NBT) during phagocytosis (7).

Cohn and Hirsch (9) have shown that granuleassociated hydrolytic enzymes shift toward the soluble fraction after phagocytosis in rabbit peritoneal leukocytes, and Zucker-Franklin and Hirsch (10) using electron microscopic techniques verified this release as being into the phagocytic vacuole. Also using electron microscopic techniques, Quie, White, Holmes, and Good (8) reported diminished autophagic and phagocytic vacuole formation in the CGD granulocytes after phagocytosis of heat-killed bacteria. The latter observation suggested that degranulation was impaired.

The purpose of our study was to quantify by chemical methods the release of granule-associated enzymes into a soluble form by leukocytes from human controls and CGD patients after phagocytosis. An electron microscopic study of peroxidase release was also made because of the sensitivity and specificity of the reactions involved in visualizing that cellular process. Our findings 
are that the release of granule-associated enzymes into soluble compartments is quantitatively and qualitatively similar in control and CGD leukocytes.

\section{METHODS}

Isolation and preparation of human leukocytes. $50 \mathrm{ml}$ of peripheral blood was collected by venipuncture from five control human subjects and four patients with CGD, identified by the quantitative NBT test (7). Control subjects were young adults with acute bacterial infections. The proportion of granulocytes was similar in all cases, circa $80 \%$ of the total white blood-cell count (WBC). The blood was collected in plastic disposable syringes previously rinsed with sodium heparin. ${ }^{1}$ The syringes were inverted and the red cells were sedimented at $37^{\circ} \mathrm{C}$ for $1 \mathrm{hr} .3$ volumes of $0.87 \%$ $\mathrm{NH}_{4} \mathrm{Cl}$ were added to the leukocyte-rich supernatant, mixed, and centrifuged at $250 \mathrm{~g}$ for $5 \mathrm{~min}$. The leukocyte pellet was washed twice and suspended in Krebs-Ringer phosphate buffer at $\mathrm{pH} 7.4$ at a concentration of $15 \%(\mathrm{v} / \mathrm{v})$.

Preparation of particles for ingestion and incubation technique. Zymosan, ${ }^{2}$ starch prepared from Amaranthus caudatus seeds (11), polystyrene spherules, ${ }^{3}$ or $E$. coli $\mathrm{K}-12$ (cultured on Difco antibiotic medium No. 3, washed twice, then heat-killed at $70^{\circ} \mathrm{C}$ for $30 \mathrm{~min}$ ), were suspended in Krebs-Ringer phosphate, $\mathrm{pH}$ 7.4. The particles were incubated for $30 \mathrm{~min}$ at $25^{\circ} \mathrm{C}$ with saline containing $10 \%(\mathrm{v} / \mathrm{v})$ fresh human serum, and the serum was decanted after centrifugation. Control tubes containing buffered normal saline without particles were treated similarly. Incubations were carried out in siliconized $125-\mathrm{ml}$ Erlenmeyer flasks labeled "resting" and "phagocytizing" and contained a final volume of $15 \mathrm{ml}$ Krebs-Ringer phosphate buffer, with a final concentration of glucose, $10 \mathrm{~mm}$, leukocytes, $2-4 \%$ by volume, and serum-treated buffered saline or particles at a final particle to cell ratio of $20-40$ to 1 . Incubations were performed for 30-60 min in a Dubnoff metabolic shaker water bath with an excursion of $3 \mathrm{~cm}$ at a speed of 50 excursions $/ \mathrm{min}$.

Preparation of subcellular fractions. The incubation medium and cells (see above) were transferred to chilled 40-ml siliconized glass conical tubes and centrifuged for 10 min at $4^{\circ} \mathrm{C}$ and $250 \mathrm{~g}$. The cell button was then washed once with cold $0.34 \mathrm{M}$ sucrose (buffered to $\mathrm{pH} 7.4$ with bicarbonate) and centrifuged at $250 \mathrm{~g}$ for $10 \mathrm{~min}$. The supernatant fluids were combined and the exact volume determined. The cell button was suspended in cold $0.34 \mathrm{~m}$ sucrose and homogenized in a $50 \mathrm{ml}$ glass cylinder ${ }^{4}$ with a Teflon pestle for 5 min at $4^{\circ} \mathrm{C}$ using a motor-driven homogenizer 5 at a rheostat setting of 30 . The homogenate was centrifuged for $10 \mathrm{~min}$ at $250 \mathrm{~g}$ and $4^{\circ} \mathrm{C}$, the supernatant removed, and the button again homogenized in sucrose using the same technique. The whole homogenate was then combined, the volume recorded, and an aliquot removed for analysis to determine recovery of the enzyme in the various subcellular fractions. The homogenate was centrifuged for $10 \mathrm{~min}$ at $250 \mathrm{~g}, 4^{\circ} \mathrm{C}$, and then the button was washed once in $0.34 \mathrm{M}$ sucrose and again centrifuged. The residual button contained nuclear debris, cellular membranes, and rare unbroken cells. This button was resuspended in $0.34 \mathrm{M}$ sucrose and labeled

1 Liquaemin sodium "10," Organon, Inc., West Orange, N. J.

2 Nutritional Biochemicals Corporation, Cleveland, Ohio.

3 Bacto-Latex, Difco Laboratories, Inc., Detroit, Mich.

4 Arthur H. Thomas Co., Philadelphia, Pa.

5 Multimix model, Lourdes Instrument Corp. Brooklyn, N. Y. "debris." The supernatant fluids were combined and centrifuged for $1 \mathrm{hr}$ at $100,000 \mathrm{~g}$ in a Spinco ultracentrifuge at $4^{\circ} \mathrm{C}$. The supernatant fraction was decanted and the granule fraction was resuspended in $0.34 \mathrm{M}$ sucrose; the volumes of the supernatant, granule, and debris fractions were recorded. Enzyme specific activities were expressed as units $\mathrm{min}^{-1} \mathrm{mg}^{-1}$ protein, and total activities were calculated from the total protein content of each fraction. Thus four fractions were obtained, i.e., external medium, debris, sedimentable granules, and supernatant fluid.

Enzyme determinations. Acid and alkaline phosphatase and beta glucuronidase were assayed with the appropriate $p$-nitrophenyl substrate, ( $p$-nitrophenyl phosphate or $p$-nitrophenyl glucuronide ${ }^{6}$ ) in a final volume of $1 \mathrm{ml}$ in the presence of $0.1 \%(\mathrm{w} / \mathrm{v})$ Triton X 100.7 Acid phosphatase and beta glucuronidase incubations were carried out at $37^{\circ} \mathrm{C}$ in sodium acetate buffer, $50 \mathrm{~mm}, \mathrm{pH} 5.0$, and the reaction was stopped with $2 \mathrm{ml}$ sodium hydroxide $0.1 \mathrm{~N}$. Alkaline phosphatase incubations were carried out in glycine buffer $0.25 \mathrm{M}, \mathrm{pH} 10.0$ and magnesium chloride $10 \mathrm{~mm}$; the reaction was stopped with $2 \mathrm{ml}$ sodium hydroxide $0.08 \mathrm{M}$. Under the conditions used, the enzymatic determinations were linear with respect to time and protein concentrations. Peroxidase was assayed by the method of Maehly (12). Catalase was determined by the method of Chantrenne as modified by Baudhuin, Beaufay, Rahman-Li, Sellinger, Wattiaux, Jacques, and deDuve (13).

Ultrastructural localization of peroxidase activity. White cells were prepared, and ingestion studies were performed as described above except that the medium contained $10 \%$ $(\mathrm{v} / \mathrm{v})$ fresh human serum. Ingestion was allowed to proceed for $15 \mathrm{~min}$. After spinning down the cells at $250 \mathrm{~g}$ and decanting the medium, the cells were resuspended in the fixative, which consisted of glutaraldehyde $2 \%$, buffered to $\mathrm{pH} 7.2$ with $0.067 \mathrm{M}$ cacodylate- $\mathrm{HCl}$ containing $\mathrm{CaCl}_{2}, 1$ mM. Fixation was at room temperature for $1 \mathrm{hr}$. After washing three times in the cacodylate buffer containing sucrose $(120 \mathrm{mM})$, the cells were transferred to the incubation medium for the ultrastructural localization of peroxidase activity by the method of Graham and Karnovsky (14). Incubation was for $20 \mathrm{~min}$ at room temperature. After washing three times in Tris- $\mathrm{HCl}$ buffer, $0.05 \mathrm{M}, \mathrm{pH} 7.6$, the cells were postfixed in buffered osmium tetroxide, and prepared for electron microscopy by standard methods previously described (14).

\section{RESULTS}

Since Cohn and Hirsch (9) noted maximal release of granular enzymes into the soluble fractions between 30 and $60 \mathrm{~min}$ after initiation of phagocytosis, differences in maximal granule release should be evident by that time. To obviate differences due to the nature of the particle itself, we obtained results using zymosan, starch, and polystyrene particles, and heat-killed E. coli. As shown in Figs. 1 and 2 there was a loss of acid and alkaline phosphatase, beta glucuronidase, and peroxidase, from the granules into the soluble fractions during phagocytos:s by human CGD leukocytes as well as by control leukocytes.

Scrutiny of the actual numbers represented by the

${ }^{6}$ Sigma Chemical Co., St. Louis, Mo.

${ }^{7}$ Rohm \& Haas Co., Philadelphia, Pa. 
bars in Figs. 1 and 2 revealed no significant differences between the control and CGD cells, although the differences between resting and phagocytizing cells of each category were indeed significant at $P$ values of 0.05 or less. One interesting feature that emerged was that the distribution of beta glucuroniclase was different in resting ('GD cells from that in normal leukocytes. The granules in the latter contained twice as much of the total enzyme as those of the former, and the net release in the case of phagocytizing CGD cells was therefore less than for control cells. The proportion of granule-bound enzyme decreased comparably during phagocytosis in both categrories of cell. Finally, in this context, we noted that for none of these enzymes did the CGD cells exhibit a lower total activity than normal cells.

By "soluble fraction" in Figs. 1 and 2 we mean the combined extracellular incubation medium and the supernatant fraction from the homogenization. Table I shows the distribution of soluble enzyme between these two compartments. Catalase, $90 \%$ of which is normally in the soluble fraction of resting cells also shifted out of the cell during phagocytosis. We noted that during uptake of larger particles, there was a greater shift of

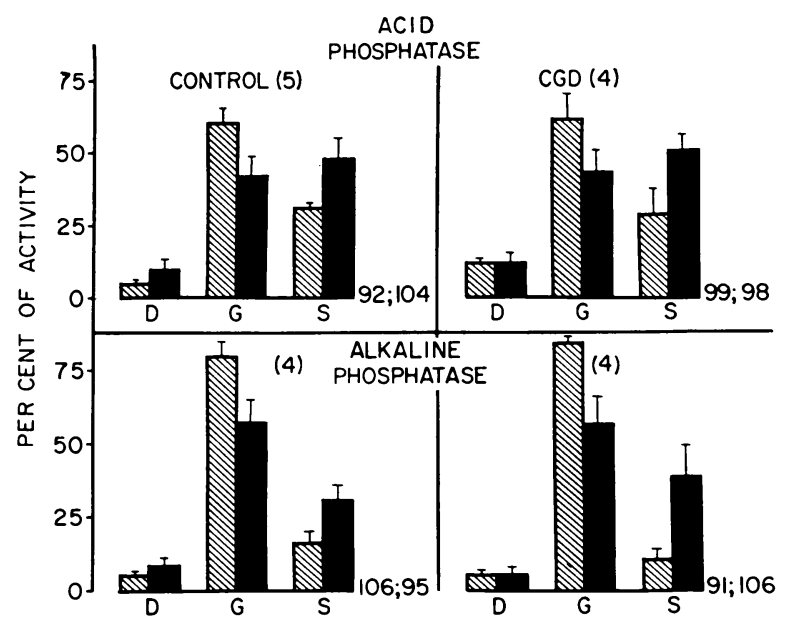

FigLRE 1 Subcellular distribution of acid phosphatase and alkaline phosphatase. The hatched bars represent resting cells and the solid bars represent phagocytizing cells. The number of subjects studied is indicated at the top of each graph. Measurements on three controls and three CGD patients were carried out after $30 \mathrm{~min}$ incubation. The other measurements were made on cells from additional subjects, after $60 \mathrm{~min}$ of incubation. Since the data for the two time periods were very similar, they were combined. Starch particles or heat-killed $E$. coli were used for phagocytosis. No differences were noted with respect to release of enzymes from the granules. (However, see Fig. 3.) The percentage of enzyme activity recovered from the subcellular fractions compared to the whole homogenate is indicated at the right of each bar graph; resting cells on the left and phagocytizing cells on the right. The sem is indicated above each bar. See text for method of preparation of the debris $(D)$, granule $(G)$, and soluble $(S)$ fractions.

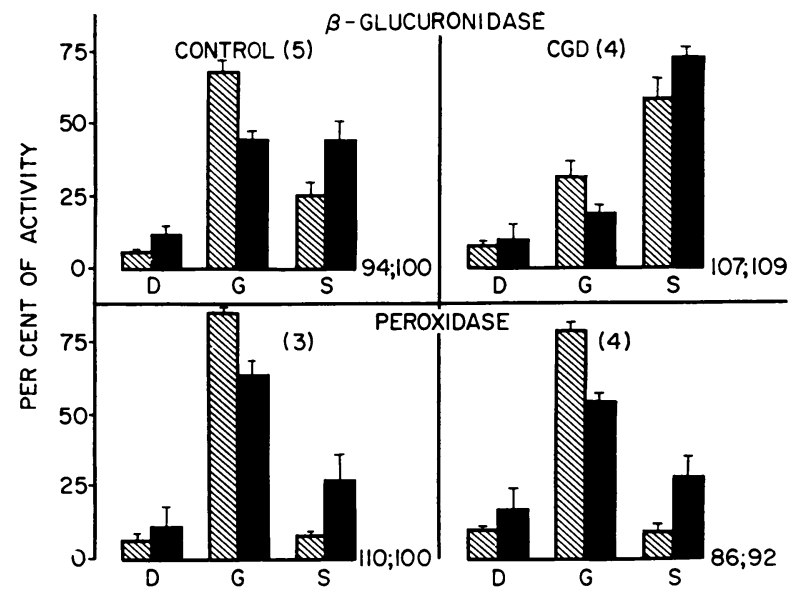

Figure 2 Subcellular distribution of beta glucuronidase and peroxidase. Conditions were as indicated for Fig. 1.

enzyme into the extracellular phase than for smaller particles (Fig. 3), i.e. during phagocytosis of starch and zymosan (circa $3 \mu$ diameter) more enzymatic activity appeared extracellularly than with $E$. coli and latex (circa $0.8 \mu$ diameter).

Electron microscopic studies of the release of granule enzymes were confined to myeloperoxidase because of the specificity and sensitivity of the method available, as mentioned earlier. The pictures confirmed the release of this granular enzyme into the phagocytic vacuole 15 min after phagocytosis of zymosan particles in both control and CGD leukocytes (Fig. 4).

Both normal and CGD neutrophils exhibited numerous large granules, which stained strongly for peroxidase activity (Fig. 4a). Various other granules did not react. This is in accord with the cytochemical observations of others on normal human and rodent cells (1417). After ingestion of zymosan particles had occurred. much peroxidase activity was observed within the phago-

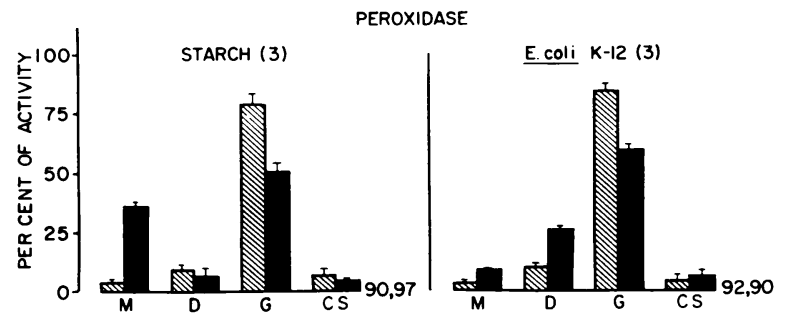

Figure 3 Subcellular distribution of peroxidase $30 \mathrm{~min}$ after phagocytosis of smaller (E. coli $\mathrm{K}-12$ ca. $1 \mu$ ) and larger ( starch ca. $3 \mu$ ) particles. The incubation medium is indicated by $\mathrm{M}$ and the intracellular soluble fraction is indicated by $C S$. The remaining fractions $D$ and $G$ indicate cellular debris and total sedimentable granules, respectively. Results include studies from two CGD patients and one control subject. Since no differences were observed, they are combined. 


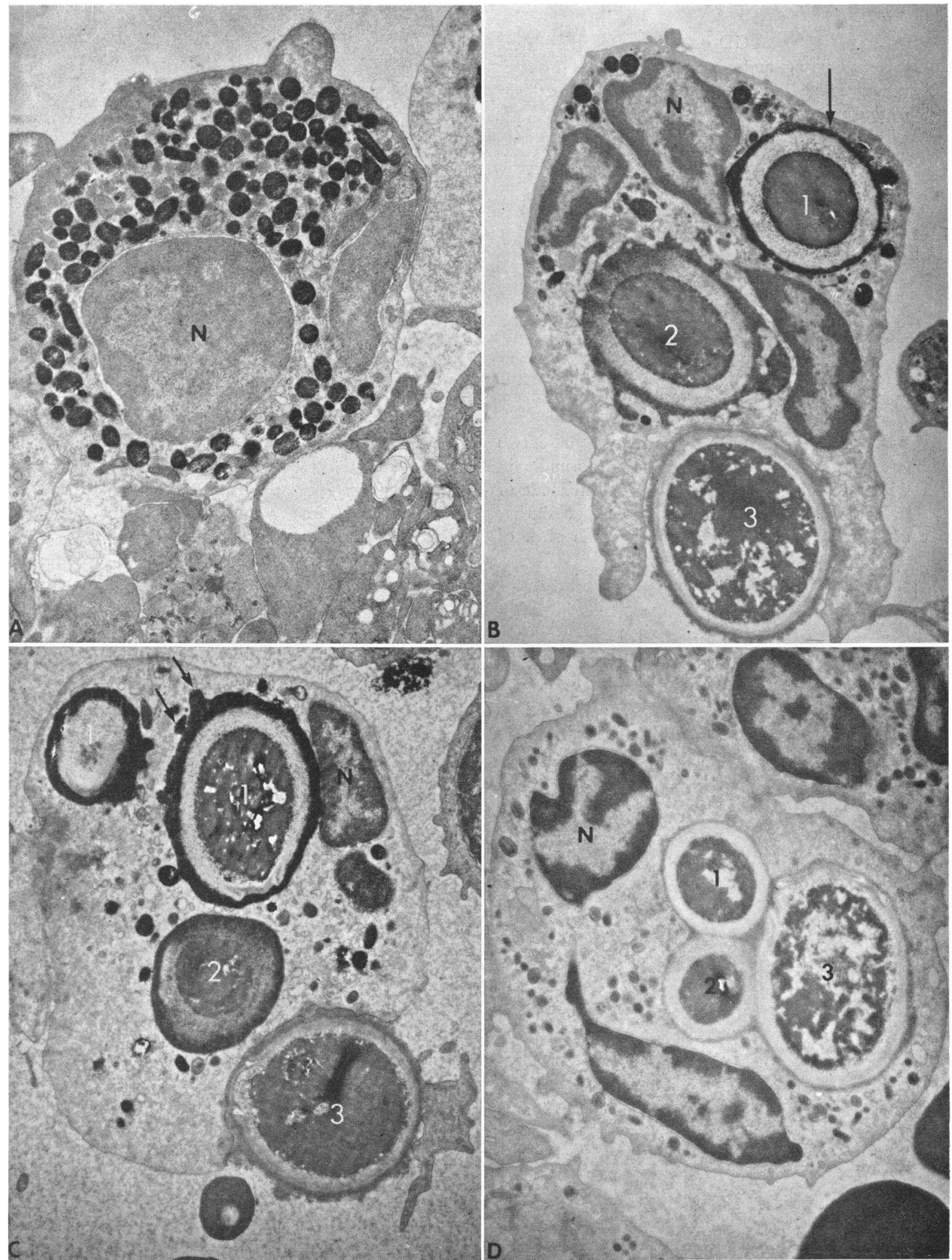

FIGURE 4 
TABLE I

Percentage of Soluble Enzyme that is Intraor Extracellular*

\begin{tabular}{|c|c|c|c|c|c|c|c|c|}
\hline & \multicolumn{4}{|c|}{ Control } & \multicolumn{4}{|c|}{ CGD } \\
\hline & \multicolumn{2}{|c|}{ CS } & \multicolumn{2}{|c|}{$\mathbf{M}$} & \multicolumn{2}{|c|}{$\mathrm{Cs}$} & \multicolumn{2}{|c|}{$\mathbf{M}$} \\
\hline & $\mathbf{R}$ & $\mathbf{P}$ & $\mathbf{R}$ & $\mathbf{P}$ & $\mathbf{R}$ & $\mathbf{P}$ & $\mathbf{R}$ & $\mathbf{P}$ \\
\hline \multicolumn{9}{|l|}{ Acid } \\
\hline phosphatase & 73 & 32 & 27 & 68 & 62 & 37 & 38 & 63 \\
\hline \multicolumn{9}{|l|}{ Alkaline } \\
\hline phosphatase & 79 & 53 & 21 & 42 & 53 & 56 & 47 & 44 \\
\hline \multicolumn{9}{|l|}{ Beta glu- } \\
\hline curonidase & 74 & 43 & 26 & 57 & 81 & 56 & 19 & 44 \\
\hline Peroxidase & 28 & 10 & 72 & 90 & 70 & 23 & 30 & 77 \\
\hline Catalase & 79 & 61 & 21 & 39 & 59 & 39 & 41 & 61 \\
\hline
\end{tabular}

* By "soluble enzyme" we mean that which is present in the external medium after incubation (M) plus that which is present in the supernatant fraction after homogenization and high-speed centrifugation of the cells (CS). This total soluble enzyme is represented by the bars labeled " $S$ " in Figures 1 and 2. In Fig. 3 these two components of the total soluble enzyme are separately represented. " $R$ " represents resting cells, and " $\mathrm{P}$ " phagocytizing cells.

cytic vacuoles, located mainly between the particle and the bounding membrane of the vacuole. The number of peroxidase-containing granules lying free in the cytoplasm had decreased, and many images were seen of peroxidase-positive granules close to, or apparently fusing with the phagocytic vacuoles. This is in accord with the granular discharge process during phagocytosis described by Cohn and Hirsch (9), and ZuckerFranklin and Hirsch (10). No differences could be observed between normal and CGD cells. Indeed, in almost every case where a particle had been ingested there was peroxidase within the phagocytic vacuole, around the particle. When $\mathrm{H}_{2} \mathrm{O}_{2}$ was omitted from the incubation media, no staining was obtained (Fig. 4d). Cyanide, $10^{-4}-10^{-8} \mathrm{M}$, inhibited the reaction. The electron microscopical studies therefore confirm the release of peroxidase into the phagocytic vacuole $15 \mathrm{~min}$ after phagocytosis of zymosan particles in both control and CGD leukocytes.

\section{DISCUSSION}

This quantitative investigation of the shifts of granuleassociated enzymes in human peripheral blood leukocytes from normal and CGD subjects, during phagocytosis of a variety of opsonized particles, indicated that the disease is apparently not characterized by faulty degranulation, as indicated by the release of typical hydrolases. The subcellular distribution patterns of leukocytes from either human controls or from patients with chronic granulomatous disease were obtained for acid and alkaline phosphatase and peroxidase after either a $30 \mathrm{~min}$ or a $1 \mathrm{hr}$ incubation at $37^{\circ} \mathrm{C}$. Both the distributions and the patterns of release were found to be very similar at those times. On the other hand, beta glucuronidase was proportionately higher in the soluble fractions of the CGD leukocytes at rest than in that fraction of control leukocytes at rest. We cannot as yet assess the significance of this finding, except to observe that it suggests heterogeneity of the granule population.

The diminished proportion of total enzyme activity in the granule fraction after phagocytosis was indeed balanced by the increased proportion of total soluble enzyme at the end of the incubation, and the overall recoveries were generally good. The shift of a soluble intracellular enzyme such as catalase into the extracellular media during this period implies that some soluble, as well as granular enzymes leaked out of the cells. The movement of granular enzymes could be via passage into incompletely sealed off phagocytic vacuoles. It may be noted that for normal cells the data for the soluble fractions of phosphatases and $\beta$-glucuronidase were very similar, while peroxidase exhibited a different pattern. This again suggests heterogeneity of the granule population. This distinction between the hydrolases and peroxidase was not noted for CGD cells. We have no indication as yet of the mode of exit of the soluble enzyme catalase.

The electron microscopic studies of peroxidase release

FIGURE 4 Myeloperoxidase activity. (A) Neutrophil from blood of mother (heterozygotic carrier) of one of CGD patients reacted for myeloperoxidase activity. Large granules stain intensely. Other granule types do not stain. Neutrophils from normal controls and CGD patients are entirely similar in staining reaction and apparence. $N=$ nuclear lobe. $\times 12,000$. (B) Neutrophil from CGD patient. Two particles of zymosan have been ingested (1 and 2). Peroxidase is present in the phagocytic vacuole around particle 1 , (arrow) and possibly around particle 2, although the density around the latter may represent only unstained contents of discharged granules (see Fig. $4 \mathrm{D}$ ). There are few free peroxidase-positive granules in the cytoplasm. Particle 3 has not yet been completely ingested, and there is no staining for peroxidase around it. The slight density around the particle represents the capsule of the zymosan particle. Compare particles 1 and 3. Cells from normal controls have an entirely similar appearance. $N=$ nuclear lobe. $\times 11,000$. (C) Neutrophil from another CGD patient. Particles 1,2 , and 3 as in Fig. 4 B. At arrows, granules are apparently fusing with, and discharging into, the phagocytic vacuole. $N=$ nuclear lobe. $\times 8000$. (D) Neutrophil from same CGD patient as in Fig. $4 \mathrm{C}$, reacted in the absence of $\mathrm{H}_{3} \mathrm{O}_{\mathrm{s}}$. Slight density in phagocytic vacuoles around particles $(1,2,3)$ represents contents of discharged granules, but there is not staining for peroxidase activity. A number of granules in the cytoplasm have slight density, but are also negative for peroxidase activity. (Compare with Fig. 4 A-C) $. N=$ nuclear lobe. $\times 8000$. 
demonstrated clearly that this lysosomal enzyme could be found in intracellular phagocytic vacuoles, offering strong confirmation of the biochemical data.

These quantitative and qualitative studies would not support the suggestion (8) that one deficiency of the CGD leukocyte is its failure to degranulate in an hour after ingestion of bacteria. Under the conditions of our experiments, it seems clear that degranulation does occur normally after the ingestion of a variety of opsonized particles. ${ }^{8}$

\section{ACKNOWLEDGMENTS}

This work was supported by U. S. Public Health Service research grants AI-03260 and AI-08173, and by a grant from the John A. Hartford Foundation.

Dr. Baehner is a U. S. Public Health Service Special Research Fellow of the National Institute of Arthritis and Metabolic Diseases.

\section{REFERENCES}

1. Holmes, B., P. G. Quie, D. B. Windhorst, and R. A Good. 1966. Fatal granulomatous disease of childhood. An inborn abnormality of phagocytic function. Lancet. 1: 1225 .

2. Kaplan, E. L., T. Laxdal, and P. G. Quie. 1968. Studies of polymorphonuclear leukocytes from patients with chronic granulomatous disease of childhood: Bactericidal capacity for streptococci. Pediatrics. 41: 591.

3. Sbarra, A. J., and M. L. Karnovsky. 1959. The biochemical basis of phagocytosis. I. Metabolic changes during the ingestion of particles by polymorphonuclear leukocytes. J. Biol. Chem. 234: 1355 .

4. Karnovsky, M. L. 1962. The metabolic basis of phagocytosis. Physiol. Rev. 42: 145.

5. Holmes, B., A. R. Page, and R. A. Good. 1967. Studies of the metabolic activity of leukocytes from patients with a genetic abnormality of phagocytic function. J. Clin. Invest. 46: 1422.

6. Baehner, R. L., and D. G. Nathan. 1967. Leukocyte oxidase. Defective activity in chronic granulomatous disease. Science. 155: 835.

8 After submission of this manuscript, the paper of Kauder, Kahle, Moreno, and Partin appeared (18) in which the authors reach the same conclusion on the basis of morphologic data.
7. Baehner, R. L., and D. G. Nathan. 1968. Quantitative nitroblue tetrazolium test in chronic granulomatous disease. N. Engl. J. Med. 278: 971.

8. Quie, P. G., J. G. White, B. Holmes, and R. A. Good. 1967. In vitro bactericidal capacity of human polymorphonuclear leukocytes: diminished activity in chronic granulomatous disease of childhood. J. Clin. Invest. 46: 668.

9. Cohn, A. Z., and J. G. Hirsch. 1960. The influence of phagocytosis on the intracellular distribution of granuleassociated components of polymorphonuclear leucocytes. J. Exp. Med. 112: 1015

10. Zucker-Franklin, D., and J. G. Hirsch. 1964. Electron microscope studies on the degranulation of rabbit peritoneal leukocytes during phagocytosis. J. Exp. Med. 120: 569.

11. MacMasters, M. M., P. D. Baird, M. M. Holzapfel, and C. E. Rist. 1955. Preparation of starch from Amaranthus cruentus seed. Econ. Bot. 9: 300.

12. Maehly, A. C. 1954. The assay of catalases and peroxidases. In Methods of Biochemical Analysis. Interscience Publishers, Inc. New York. D. Glick, editor. 1: 385.

13. Baudhuin, P., H. Beaufay, Y. Rahman-Li, O. Z. Sellinger, R. Wattiaux, P. Jacques, and C. de Duve. 1964. Tissue fractionation studies. 17. Intracellular distribution of monoamine oxidase, aspartate amino transferase, alanine amino transferase, $\mathrm{D}$-amino acid oxidase and catalase in rat-liver tissue. Biochem. J. 92: 179.

14. Graham, R. C., and M. J. Karnovsky. 1966. The early stages of absorption of injected horseradish peroxidase in the proximal tubules of mouse kidney: ultrastructural cytochemistry by a new technique. J. Histochem. Cytochem. 14: 291.

15. Yamada, E., and R. Yamauchi. 1966. Some observations on the cytochemistry and morphogenesis of the granulocytes in the rat bone marrow as revealed by electron microscopy. Acta Haem. Jap. 29: 530 .

16. Enomoto, T., and T. Kitani. 1966. Electron microscopic studies on peroxidase and acid phosphatase reaction in human leukocytes (In normal and leukemic cells and on the phagocytosis). Acta Haematol. Jap. 29: 554.

17. Daems, W. T., and M. van der Ploeg. 1966. On the heterogeneity of human neutrophilic leucocyte granules. In Electron Microscopy. R. Uyeda, editor. Maruzen Co., Ltd., Tokyo. 2: 83 .

18. Kauder, E., L. L. Kahle, H. Moreno, and J. C. Partin. 1968. Leukocyte degranulation and vacuole formation in patients with chronic granulomatous disease of childhood. J. Clin. Invest. 47: 1753 